\title{
Ring shake and structural characteristics of a chestnut (Castanea sativa Miller) coppice stand in northern Piedmont (northwest Italy)
}

\author{
N Macchioni ${ }^{1}$, M Pividori 2 \\ ${ }^{1}$ Istituto per la Technologia del Legno, CNR, via Biasi, 75, 38010 San Michele all'Adige (TN); \\ 2 Dipartimento di Agronomia, Selvicoltura e Gestione del Territorio, Università di Torino, \\ via $L$ da Vinci, 44, 10095 Grugliasco (TO), Italy
}

(Received 8 August 1994; accepted 20 March 1995)

\begin{abstract}
Summary - In a chestnut coppice located in Torre Canavese (Province of Turin) in northwest Italy, on a surface of $3080 \mathrm{~m}^{2}$, a structural analysis of the population was carried out and, after coppicing, the frequency and distribution of ring shake in stems was studied. The aim of this work was to observe the presence of ring shake in shoots, stools and standards, and to evaluate the possible relationships existing between these data and those characterizing the individual stems, the individual stools and the entire population from the structural and typological standpoint. From the results, it emerges that $96.2 \%$ of standards and $37.9 \%$ of shoots are involved in the defect and only $51 \%$ of stools present shoots with ring shake. The distribution of ring shake in the stems is concentrated in the middle third of the radius, and as much as $50 \%$ of the defect appears in correspondence with the growth rings for the years 1971,1972 and 1973. The distribution of stools with shoots affected by ring shake is not uniform over the plot.
\end{abstract}

chestnut / coppice / ring shake / structure

Résumé - Roulure et caractéristiques structurelles d'un peuplement de taillis de châtaignier dans le nord du Piémont (nord-ouest de l'Italie). Dans un taillis de châtaignier de Torre Canavese (Turin, nord-ouest de l'talie), sur une surface de $3080 \mathrm{~m}^{2}$, on a analysé la structure du peuplement et, après la coupe, la fréquence et la distribution de la roulure des fûts. Le but fixé était observer la présence de la roulure des rejets, des souches et réserves et d'évaluer les éventuelles relations entre les données et celles qui caractérisent (structurellement et typologiquement) les tiges ou les souches individuellement ainsi que le peuplement entier du point de vue structurel et typologique. Les résultats indiquent que $96,2 \%$ des réserves et $37,9 \%$ des brins sont affectés par le défaut alors que seulement $51 \%$ des souches présentent des rejets roulés. La distribution des roulures dans le fût est concentrée dans le tiers central sur le rayon et $50 \%$ du défaut apparaît sur les cernes des années 1971, 1972 et 1973. La distribution des souches avec rejets roulés n'est pas uniforme sur la parcelle.

châtaignier / taillis / roulure / structure 


\section{INTRODUCTION}

The demand for stocks of good quality chestnut on the part of the wood-transformation industry throughout southern Europe is high, but only in the presence of a market developed in all its components can such a demand be satisfied. The existence of coppices as the well-nigh exclusive producers of workable timber (Bagnaresi and Giannini, 1979) does not appear sufficient to offer any improvement in the situation in that, but for a very low percentage of the wood produced, in the past this type of cultivation failed to make available material with good characteristics of size and quality for sawing.

As far as the Italian situation in particular is concerned, the fact that a timber market has developed in neighbouring France has meant that users have available a sufficiently steady source of supply quality wooden stock at fair prices, and hence have not felt the need to press for any improvement of internal production and to organize a market with similar characteristics. Such a need, however, now appears to emerge owing to the fact that material is no longer arriving from the former Yugoslavia and to the fact that the demand on the French market has increased as a result of competition for timber from the Spanish and Portuguese transformation industries.

According to those operating in the woodtransformation sector, material of Italian production would seem to suffer to a greater extent from the presence of ring shake than does the French chestnut. This belief is probably due to the fact that the French timber merchants, who are frequently also the users of the coppice, which they divide into four or five different assortments of stock according to the final destination of the product, select beforehand the timber to be put on sale precisely on the basis of the presence or otherwise of ring shake, rather than to an effectively lower incidence of the defect in timber of French origin. In fact, ring shake seems to be the only real limit to the spread and use of chestnut wood on a scale closer to the availability of this wood in the countries of the Mediterranean basin (table I).

\section{Definition of ring shake}

Ring shake is a crack that develops on longitudinal-tangential surfaces of the wood and leads to partial or total detachment prevalently between two consecutive growth rings. The Italian species that are most affected by ring shake are silver fir (Abies alba Mill) and chestnut. Studies carried out on the problem of ring shake in chestnut wood indicate as fundamental the following points (Chanson et al, 1989):

i) Chestnut is a tree that is very sensitive to traumas; injuries due to felling operations, fire and the action of animals always favour the appearance of so-called traumatic ring shake.

ii) It clearly emerges that certain chestnut trees have a particularly low radial mechanical strength, which predisposes them to the appearance of ring shake during any stage of utilization of the wood. In this connection, mechanical methods are being developed (Frascaria et al, 1992; Macchioni, 1992b, 1995) for the evaluation of this general "fault"

Table I. Chestnut cultivated areas (coppice and high stands) in EU countries (from Bourgeois, 1992).
Country

France

Italy

Spain

Portugal

Great Britain

Greece

Germany
Surface (ha)

1000000

700000

130000

32000

30000

17000

2000 
of the cambium, but the predisposing factors (genetic, edaphic, possible shortage of oligoelements, etc) are as yet unknown.

iii) The opening-up of ring shake upon felling and during steam treatment is directly linked to the presence of an "internal deformation potential", the value of which appears to depend, as in the case of beech, upon the type of silviculture applied. It is therefore the disposition of the internal growth stresses that leads to the appearance of cracks, which in chestnut frequently develop in the form of ring shake.

iv) During drying, the following factors are believed to favour the opening-up of cracks:

- the size of the pieces sawn: the bigger they are, the higher the incidence of ring shake;

- the presence of severe moisture gradients;

- the heterogeneity of shrinkage;

- the big differences of permeability between adjacent areas of wood.

Ring shake due to points ii), iii) and iv) is defined as healthy ring shake.

The by now numerous studies to be found in the literature have, however, always had reference to stems sampled within a population according to criteria linked for the most part to qualitative factors, that is, selecting a part of the stems that could be considered suitable for "sawing". The present study, instead, has afforded the opportunity of making recordings on an entire population during coppicing. It will therefore be possible to add new observations on the spread of the defect and on the possible correlations with the silvicultural parameters of the population and the morphological parameters of the individual stems.

\section{PURPOSE}

The purpose of the present work is to assess the distribution of ring shake within an entire chestnut coppice population. The aim is to observe the presence of ring shake on coppice shoots, stools and standards and to evaluate the possible relationships existing between these data and those that characterize the individual stems, the individual stools and the entire population from the structural and typological points of view. In contrast to what may be found in the literature on the subject, it will moreover be possible to throw light on the true incidence of the defect in an entire population, through the systematic checking of all the shoots, the diffusion of ring shake in the stems that belong to individual stools and finally its incidence among chestnut standards.

This work is to be considered the sequel to a study programme into the problem of ring shake in chestnut wood conducted at the Dipartimento di Agronomia, Selvicoltura e Gestione del Territorio of the University of Torino (EEC-FOREST Project: "New methods of silviculture and innovative technologies for the exploitation of chestnut wood as raw material for industrial manufacturing processes"). In this framework, studies of a silvicultural type and of a technological type are combined in one and the same work.

\section{MATERIALS AND METHODS}

\section{Description of population}

The population under examination is an aged coppice having a monoplanar structure with prevalence of chestnut, located in the commune of Torre Canavese (Province of Turin) (fig 1) at an altitude of $417 \mathrm{~m}$ above sea level. The plot (surface area: $3080 \mathrm{~m}^{2}$ ) is prevalently flat ( $3 \%$ slope in the south-north direction) and in a remote past was probably cultivated, in that the top $30 \mathrm{~cm}$ of soil profile appear to be turned over (ploughed), with stones and rocks removed. The geological substrate consists of polygenic glacial deposits of the morainal amphitheatre of Ivrea. The climate is characterized by an annual mean rainfail (1926-1970 period) of $1148 \mathrm{~mm}$ of an equinoc- 


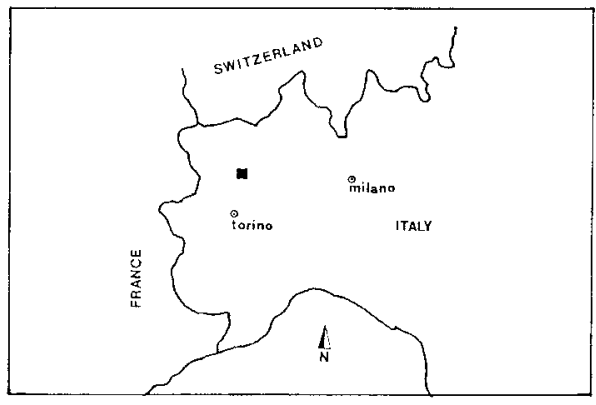

Fig 1. Geographical location of the study area.

tial type, with an absolute maximum in spring and an absolute minimum in winter. As a whole, the pattern of rainfall can be defined as of the Alpine sublittoral type. The annual mean temperature, calculated for the same period, is $12.04{ }^{\circ} \mathrm{C}$; the hottest month is July (mean temperature, $22.60^{\circ} \mathrm{C}$ ) and the coldest is January (mean temperature, $0.43^{\circ} \mathrm{C}$ ). The wooded soil surface of the area consists, for $95 \%$ of the basal area, of chestnut, and, for the remaining $5 \%$, of English oak, black locust, hornbeam, cherry and birch. In the general complex of the chestnuts of the area, the stretch of woodland studied is representative of those in better conditions (Fenaroli, 1945) as regards fertility, climatic conditions and accessibility, and hence offers greater production potential and vocation. The choice of this population was dictated not only by the characteristics favourable to a silviculture of a productive type, but also by the assured presence of ring shake in the shoots, identified through a historical inquiry among the local users and the owner of the plot.

\section{Parameters recorded in the coppice}

We proceeded initially to the topographic location of each chestnut stool, both living and dead, to its identification by means of a number and to the numbering of all the live shoots present. In the cases of stools of an extremely irregular shape or of large dimensions, the isolated portions that did not present continuity in the wood with the neighbouring portions of the stool were considered as autonomous stools. Hence, for each stool and each shoot, the following parameters were recorded or measured:

\section{Stools}

Diameter of stool: The maximum diameter of the stool was measured and the one perpendicular to it.

Distance: The distances of each stool from the four nearest stools were measured, the measurement being made on the bases of the two proximal shoots.

Number of shoots (alive and dead).

Height of insertion of shoots: The distance was measured between the point of insertion of the shoot inserted at the highest point of the stool and the ground surface.

\section{Coppice shoots}

Social position: As distinctive parameters, the breast-height diameter, the tree height and the area of incidence of the crown were used, comparing them with those of the other shoots of the population, distinguishing three classes: dominant, codominant and dominated or overtopped.

Orientation: Identification of the position of the shoot on the stool referred to the four cardinal points.

Sweep: The maximum height of the curvature at the foot of the trunk and the deflection of the incurvation (ie, the distance between the foot of the trunk and the plumb line positioned at the highest point of the arc of curvature) were measured.

Verticality: The deflection at the base with respect to a plumb line of $4 \mathrm{~m}$ (length of a theoretical high-quality stock) in height, set resting against the stem, was measured.

Diameter at $1.30 \mathrm{~m}$ : Obtained as the resultant of 2 diameters recorded crosswise at breast height.

In addition to the mean diameter, also calculated were the following:

Ovality of stem: Understood as the ratio between the larger and the smaller diameters measured at breast height.

Height: Dendrometric height, measured with a Blume-Leiss hypsometer.

Thickness of the crown: Understood as the difference between the total height of the tree and the height of insertion of the crown (first living nonepicormic branch).

Maximum and minimum diameter of crown: The diameter of the projection on the ground of the 
area of incidence of the crown of the shoot in the sections of maximum and minimum development was measured.

Number of cankers: The number of cankers of the bark (Cryphonectria parasitica [Murr] Barr) visible from the ground and their prevalent distribution along the trunk were recorded, distinguishing four classes of height over the total length of the trunk, without evaluations being furnished as regards their type (ie, whether active, cicatrized, etc).

Presence of epicormic branches: When present, 4 classes of "abundance" were distinguished according to the percentage of trunk (between base and first ramification of living branches) covered by epicormic branches.

Other defects of the stem: The presence of cracks due to frost, along with their vertical extension and their orientation, injuries, etc, were recorded.

Once the in-field recording phase was completed, we proceeded to coppice the chestnut crop. During cutting operations, which spared ten stems, which were left as standards, a disk was taken from each living shoot, at a height of $50 \mathrm{~cm}$. This section was deemed to be representative, in that it is on the base portion of the stem that ring shake manifests itself most, according to the recordings made by Cielo (1992) and Macchioni (1992a), whereas the presence of the defect progressively diminishes, the higher we proceed up the trunk.

\section{Parameters measured in the laboratory}

On the disks, seasoned in the laboratory, the annual growth rings were counted and measured along two radiuses: the greater length and the one perpendicular to it. The presence of the characteristic porous ring did not allow us to go beyond a precision of one-tenth of a millimeter, inasmuch as the variable dimensions of the vessels contiguous to one another rendered the passage from one ring to the next far from clear-cut.

In addition, the cases of ring shake, injury and rot present were counted and classified. The criterion of classification of ring shake, developed by Amorini (in verbis, 1994), considers ring shake on the basis of the extent of the phenomenon and assigns a value from 1 to 10 according to the portion of round angle $\left(360^{\circ}\right)$ involved in the annual ring (table II). The presence of ring shake and injury was moreover referred to the solar

Table II. Classification of types of ring shake considered as a fraction of the annual ring.

\section{Type}

1

2

3

4

5

6

7

8

9

10

\section{Fraction of annual ring}

$$
\begin{gathered}
0<x<1 / 16 \\
1 / 16<x<1 / 8 \\
1 / 8<x<1 / 4 \\
1 / 4<x<3 / 8 \\
3 / 8<x<1 / 2 \\
1 / 2<x<5 / 8 \\
5 / 8<x<3 / 4 \\
3 / 4<x<7 / 8 \\
7 / 8<x<1 \\
=1
\end{gathered}
$$

year corresponding to the annual ring in question. No data have been collected on the presence and type of growth stresses diametral checks, because they cannot be recorded on seasoned disks.

The shoots were considered not to be affected by ring shake (Class 0 ) when, in the section taken at a height of $0.50 \mathrm{~m}$, no evidence of ring shake was found or one case only of type 1 . In all the other cases, the shoots were considered as being affected by ring shake. The latter shoots were then subdivised into two classes (Class 1 and Class 2) on the basis of the seriousness of the phenomenon (table III).

The stools were classified according to two criteria: degree of dominance and incidence of shoots with ring shake.

As regards the first criterion of classification, from the analysis of the variations of the various parameters of the population, a very clear differentiation emerged between the shoots of different stools, which may be explained only in part as a result of the internal relationships of competition. In fact, it is beyond any doubt that the hierarchical distribution between the stools, as a result of competition, is clearly visible in the coppice; there remains only to define what are the fundamental parameters that are to be recorded in order to identify objectively a distinction of this sort. On the other hand, already in the studies made by Cava and Ciancio (1975) and by Bernetti (1985), right up to the latest investigations of Amorini and Fabbio (1991), there has been discussion of the concepts of dominant, codominant, subdominant or dominated stools, without, however, there being 
Table III. Classification of shoots on the basis of the intensity of the ring shake phenomenon.

Class

Intensity of ring shake

0

1

2 With one case of ring shake of types $5,6,7,8,9,10$ or more than 1 case of ring shake of an type

any precise specification of what were the decisive or fundamental characteristics for making such a distinction.

For this purpose, on the basis of the data regarding the entire population, certain parameters, both for stools and for shoots, where chosen; these are:

- number of shoots per stool;

- mean diameter of the shoots of the stool;

- mean height of the shoots of the stool;

- summation of the areas of incidence of the crowns of the shoots of the stool.

Since then it amounted to a set of independent variables with a different influence on a sample population, as a statistical test for identifying the hierarchical groups, it was decided to use cluster analysis following Ward's method. The choice of the discriminating parameters was made taking initially into consideration all the parameters and eliminating, by a process of trial and error, those that did not carry weight in the differentiation of the groups.

The second criterion of classification takes into consideration the incidence of the ring shake phenomenon. For this purpose, we proceeded to calculate the percentage of coppice shoots with ring shake out of the total of each stool. On the basis of this percentage, the stools were subdivided into 4 classes (table IV).

\section{RESULTS AND DISCUSSION}

\section{Structural characteristics of the chestnut stand}

The results (table $\mathrm{V}$ ) refer exclusively to the main population made up of chestnut; the

Table IV. Classification of stools on the basis of the percentage of shoots with ring shake.

Class Percentage of shoots with ring shake

0

1

2

3

data regarding the other species are not discussed here.

As far as the number of shoots and the size of the stools are concerned, a direct correlation was found between the two parameters, as previously reported by Cava and Ciancio (1975).

Also numerous dead shoots are present on the stools, in the ratio of almost 1:1 (1.06) with the living ones. This datum provides an indication as to the well-nigh total absence of silvicultural treatment provided in the past. The only interventions in regard to which there is information are a few cases of clearing and sporadic "plunder" cuts occurring concomitantly with the annual gathering of litter for agricultural purposes, carried on regularly up to the last decade.

\section{Stools}

The considerable variability of the diameter of the stools (table VI) and their shape (in $61 \%$ of cases semicircular or irregular) 
Table V. General characteristics of the population under study.

$\begin{array}{lcc} & \text { Real data } & \\ & & \\ n \text { of stools (live) } & 96 & 311 \\ n \text { of stools (dead) } & 21 & 68 \\ n \text { of stems } & 300 & 974 \\ \text { Mean } n \text { of shoots/stool } & 3.14 & \\ \text { Min } n \text { of shoots/stool } & 1 & \\ \text { Max } n \text { of shoots/stool } & 10 & \\ \text { Mean diameter of shoots }(\mathrm{cm}) & 18.16 & \\ \text { Min diameter of shoots }(\mathrm{cm}) & 5 & \\ \text { Max diameter of shoots }(\mathrm{cm}) & 39 & 83 \\ \text { Mean height }(\mathrm{m}) & 17.7 & 39.36 \\ n \text { of standards } & 26 & \\ \text { Basal area }\left(\mathrm{m}^{2}\right) & 12.12 & \end{array}$

Table VI. Measurements carried out on the stools $(n=96)$.

$\begin{array}{lcccc} & & & & \\ & \text { Mean } & \text { Min } & \text { Max } & S D \\ \text { Mean diameter }(\mathrm{m}) & & & & \\ \text { Mean distance }(\mathrm{m}) & 1.20 & 0.35 & 3.00 & 0.56 \\ n \text { of shoots } & 4.14 & 1.60 & 6.55 & 1.14 \\ \text { Height of insertion of shoots }(\mathrm{m}) & 3.15 & 1 & 10 & 1.80 \\ & 0.20 & 0.00 & 0.99 & 0.21\end{array}$

may be an indication of a certain difference in age between them. This fact would appear to point towards a coppicing of the population dating back a long time, dictated by reasons of a technical and economic nature (production of posts and poles for vineyards), and not of a phytosanitary nature; indeed, in this latter case, it would be relatively recent (approximately 50 years), since coppicing for phytosanitary reasons is linked principally to the appearance of canker of the bark (Bagnaresi, 1977; Regione Piemonte, 1981; Bagnaresi et al, 1984).

The mean distance between the stools of the population, and hence the number of stools per hectare, is rather low if compared with the data given in the Piedmont Forestry
Map (Regione Piemonte, 1981), but the density increases notably on the borders of the plot, which is a characteristic common to the majority of the populations of the district. This fact would lead one to presume a use of "flats" consisting of stools as landmarks.

The average height of the stools is an indication of a type of coppicing in which the stems are cut not flush to the ground, but at a certain height, with maximum heights that are close to $1 \mathrm{~m}$. Also in this case, the tallest stools are concentrated along the borders of the plot, where piles of stones and dry walls are present which are the result of past work of removing stones from the soil, when the site was undergoing agricultural cultivation. 


\section{Coppice shoots}

As far as shoots are concerned (table VII), $16 \%$ of the total did not present sweep of the trunk $(17 \%$ in dominant shoots and 13 and $16 \%$ in codominant and overtopped shoots, respectively), whereas only $0.2 \%$ of shoots proved perfectly vertical in the first 4 $\mathrm{m}$. As far as the ratio of ovality is concerned, that is, the ratio between the two perpendicular diameters measured, $26 \%$ of the shoots had a regular section at the height at which the measurement was made.

Canker of the bark affected all the stools of the population, and healthy cicatricial calluses in $60 \%$ of the cases were observed along the entire length of the stem. Also the presence of epicormic branches, which are an index of plant stress (Conedera, 1989, 1993), affected the population as a whole, but in this case their presence in more than one-half of the stem below the living crown, a characteristic considered by us to indicate plants presenting signs of greater suffering, involved $19 \%$ of the trees.

The general data were then re-aggregated in accordance with the degree of dominance of the shoots (table VIII). As a rule, the mean values were seen to drop as we proceeded from the dominant class to the dominated one. Furthermore, the dominant shoots were those that had a more favourable ratio, both between deflection and height of arcuation, and as regards the verticality of the trunk, than the codominant ones and even more so than the dominated ones, and thus presented stems having a better conformation.

As regards ovality, which was equal to 1 in $36 \%$ of the shoots in general, this showed the presence of circular stems in $30 \%$ of the dominant shoots, a percentage which rises to $39 \%$ instead, for codominant and overtopped stems.

The thickness, diameter and vertical development of the crown varied notably within the three social classes, not so much according to the position of the shoot within the stool, but rather according to the social position of the various stools, in that in general dominant stools had shoots with expanded crowns which tended to occupy the space belonging the hierarchically lower stools.

\section{Hierarchical distribution of the stools}

The subdivision of the stools into classes of dominance, performed by means of clus-

Table VII. Mean values of the main qualitative and quantitative parameters of shoots present in the population $(n=274)$.

\begin{tabular}{|c|c|c|c|c|}
\hline & Mean & Min & $\operatorname{Max}$ & $S D$ \\
\hline Mean diameter $(\mathrm{cm})$ & 18.15 & 5.00 & 39.00 & 5.370 \\
\hline Mean height $(\mathrm{m})$ & 17.8 & 5.00 & 25.00 & 3.370 \\
\hline Height of sweep (m) & 0.78 & 0.10 & 2.00 & 0.365 \\
\hline Sagitta of sweep (m) & 0.14 & 0.03 & 0.65 & 0.111 \\
\hline Verticality $(\mathrm{m})$ & 0.51 & 0.00 & 1.55 & 0.321 \\
\hline Ovality of stem & 1.07 & 1.00 & 1.73 & 0.074 \\
\hline Height of insertion of shoots (m) & 0.15 & 0.00 & 0.99 & 0.586 \\
\hline Thickness of crown $(\mathrm{m})$ & 6.65 & 1.00 & 16.00 & 2.887 \\
\hline Crown development along the stem (\%) & 35.76 & 7.69 & 77.27 & 12.860 \\
\hline Mean diameter of crown $(\mathrm{m})$ & 4.70 & 0.70 & 10.20 & 1.628 \\
\hline$n$ of cankers & 5.23 & 1 & 9 & 2.118 \\
\hline
\end{tabular}


Table VIII. Mean values of the main qualitative and quantitative parameters of the shoots subdivided into social classes.

Dominant

Codominant

33

17.29

17.90

0.76

0.13

0.45

1.05

0.13

6.53

36.29

4.65

5.44

\section{Dominated}

25

14.77

13.38

0.70

0.14

0.65

1.07

0.12

3.80

28.14

3.44

4.69 ter analysis (see earlier), led to the formation of three groups: dominant stools (29\%), codominant $(53 \%)$ and dominated $(18 \%)$. Analysis of the re-aggregated data (table IX) emphasizes how in general the main parameters tend to increase as we pass from the dominated class to the dominant one. In the case of mean height of the shoots of the stool and the data on the height of sweep and verticality, the mean values enable a clear distinction to be made between the three categories, while the ovality of the shoots and the number of cankers remain practically constant. Of some interest is the datum on the mean distance of a stool from the 4 nearest ones: dominant and dominated stools have the same distance $(3.7 \mathrm{~m})$, while the codominant ones (ie,

Table IX. Mean values of the main qualitative and quantitative parameters of the stools subdivided into social classes.

Dominant

Percentage on total

Mean distance $(m)$

Mean diameter $(\mathrm{m})$

Mean height $(\mathrm{m})$

Mean $n$ of shoots

Diameter of mean shoot $(\mathrm{cm})$

Height of mean shoot $(\mathrm{m})$

Thickness of crown (m)

Sum of crown area $\left(\mathrm{m}^{2}\right)$

Height of sweep $(\mathrm{m})$

Sagitta of sabre crowth $(\mathrm{m})$

Verticality $(m)$

Ovality of stem

Mean $n$ of cankers
29

3.7

1.6

0.23

4

21.6

19.5

7.6

92.5

0.6

0.13

0.5

1.1

5.2
Codominant

53

4.6

1.0

0.19

3

17.1

17.2

6.5

44.8

0.7

0.14

0.4

1.1

5.3

\section{Dominated}

18

3.7

0.9

0.22

2

14.2

14.0

3.4

16.5

0.5

0.12

0.6

1.1

5.1 
stools with intermediate characteristics) have a greater distance $(4.6 \mathrm{~m})$; this fact might confirm the importance of interstool competition on the evolution of the structure of the population, once it has reached this stage of ageing. The dominant stools and the dominated ones (fig 2) tend to be distributed nearer the borders of the plot, where the density is greater, the codominant ones being more towards the centre. It is possible to suppose that this situation, besides being favoured by the greater availability of light in concomitance with cuts carried out on bordering plots, may be determined by a sort of exploitation of the biological resources on the part of prevailing stools (root apparatus and photosynthetic activity) at the expense

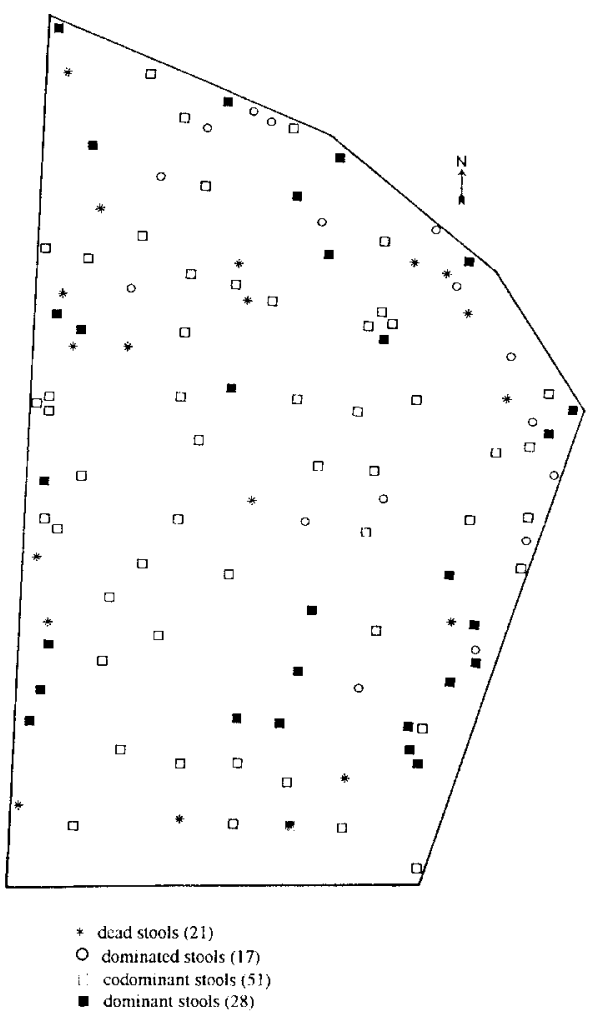

Fig 2. Location of stools on the study area with indication of their social position. of the succumbing stools. It would thus be of extreme interest to verify, in addition to the relationship between the roots and shoots of a stool (Aymard and Fredon, 1986), just what interactions exist between neighbouring stools through the presence of anastomoses of the root and the physiological mechanisms connected to them.

\section{Age of population and radial increment}

From the ring count performed on the section at a height of $50 \mathrm{~cm}$, where normally also the first year of shoot growth is included, there emerges a difference of age in the population. In fact, the plot turns out to have been cut in four consecutive phases, so that we witness the presence of four sectors having stools with shoots of 35 years old ( 37 stools, corresponding to $40 \%$ of the total), 33 years old ( 28 stools, corresponding to $29 \%$ of the total), 30 years old (14 stools, corresponding to $15 \%$ of the total) and 26 years old (15 stools, corresponding to $16 \%$ of the total). In addition, the same analysis enabled the identification of 26 standards (fig 3), which were not distinguishable at the moment of observation of the stand, except for one, all deriving from normal shoots (16) or freed shoots (9), and subdivided into two main generations, one 65 years old ( 3 coppice rotations), concentrated in the area in which the shoots are 26 years old, and the other 53 years old (two coppice rotations).

On all the shoots of the population, the current increment was calculated on the mean of the two radiuses, so that the corresponding mean curve was obtained (fig 4). This presents a general decreasing pattern, in which, excluding the first years of rapid increment, three "periods" were observed: around years 7-8 (1965-1966), 11-15 (1968-1972) and 25-27 (1982-1984), in which the radial increment was reduced to a more evident degree, followed by periods of recovery. 


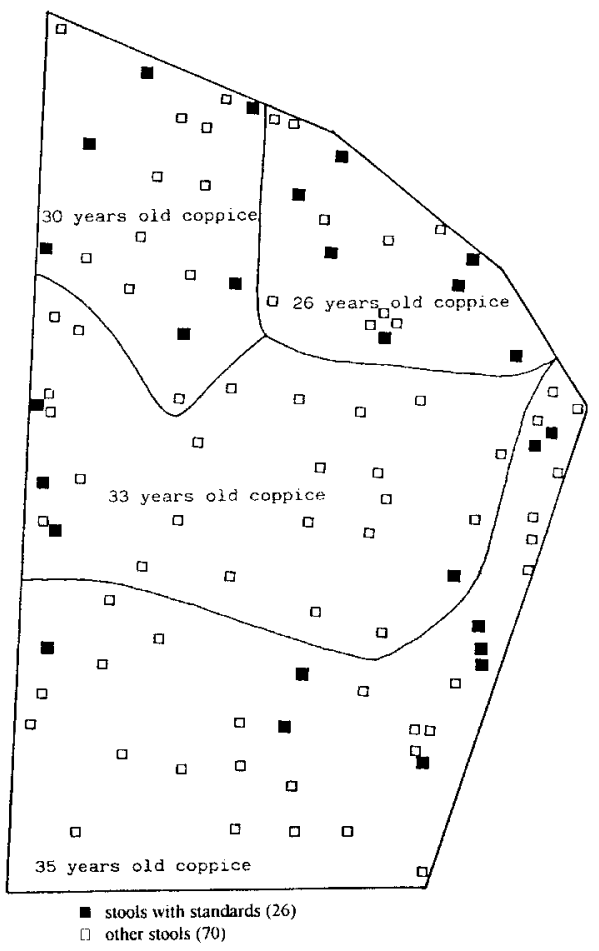

Fig 3. Location, on the study area, of standards and sectors with coppice shoots of different ages.

The curve of increment of the standards, an example of which is given in figure 5 , is in general characterized by a rather reduced initial increase, by a sharp increment following immediately on coppicing and a subsequent pattern similar to the one presented by the shoots. The aspects regarding the relations between the rhythm of radial increment of shoots, stools and standards within the population are at present under study and will form the subject of a future publication.

\section{Incidence of ring shake}

The observations made on ring shake were conducted on 264 shoots, distributed over 85 stools and 26 standards. The latter data depart from those corresponding to the observation of the standing wood because at the moment of coppicing 10 shoots were released for silvicultural aims.

Altogether 410 cases of ring shake were found, of which $278(67.8 \%)$ were on shoots and $132(32.2 \%)$ on standards, even though the standards were only $8.9 \%$ of the total stems. Among the shoots, only $37.88 \%$ (100) presented ring shake, which instead was found in $96.2 \%$ (25) of the standards. At the level of the stools, the distribution of the shoots that presented ring shake was not homogeneous but was concentrated in $51 \%$ (43) of the total.

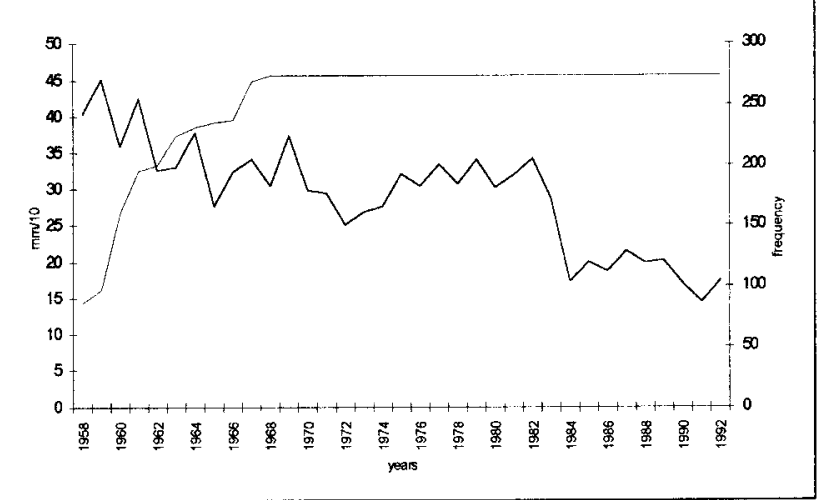

Fig 4. Current increment $(1 / 10 \mathrm{~mm})$ of radius of shoots and frequency of samples. 


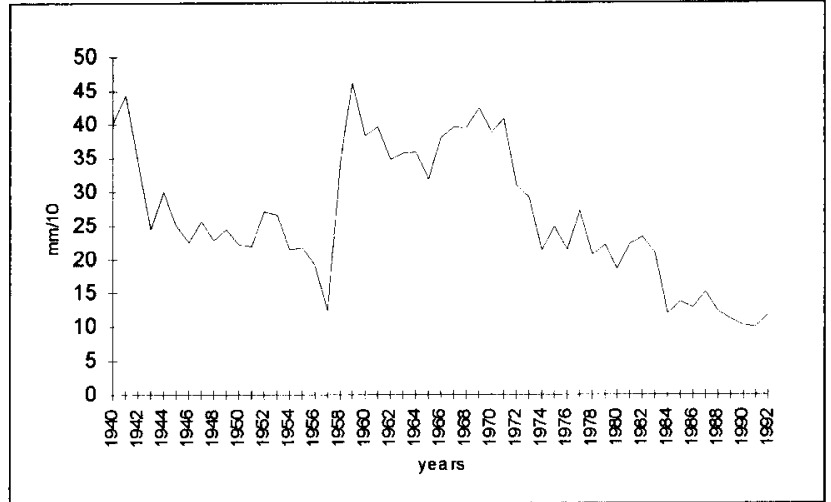

Fig 5. Current increment $(1 / 10 \mathrm{~mm})$ of radius of $53-$ year-old standards $(n=13)$.
The shoots that presented injuries and rot observed in the section made at a height of $0.5 \mathrm{~m}$ were few: $45(17 \%)$ in the first case and $8(3 \%)$ in the second. The shoots with injuries and simultaneous presence of ring shake amounted to $24(9 \%)$, and those with rot and ring shake to $4(1 \%)$. In only one case were injury and ring shake found to be contemporaneous on the same annual increment. It is not, however, possible to rule out a priori that this may have occurred also on sections different from the one observed. In fact, the distinction between traumatic ring shake and healthy ring shake is very simple in the case where ring shake and traumas are unequivocally found to be present on one and the same growth ring in a given section, but this would mean having to section an entire stem every $30-50 \mathrm{~cm}$. The only alternative would be to define as healthy all those types of ring shake to which the presence of trauma cannot be directly attributed, even if a trauma that the plant may have undergone, for example, at the height of $130 \mathrm{~cm}$, with simultaneous presence of ring shake, may leave as sole evidence behind it ring shake in the section taken at the height of $50 \mathrm{~cm}$. Hence, apart from one single case, all the cases of ring shake found were defined as "healthy".

\section{Typology and distribution of ring shake}

The majority of cases of ring shake present on the shoots (table $X$ ) was of types 1 and 2 $(69 \%)$ whereas the most serious forms (types 9 and 10), which may be defined as "total" (Giordano, 1981) in that they affected the totality of the section, were only $1 \%$. On the standards, ring shake of types 1 and 2 were lower in number $(53 \%)$, while the most serious types 9 and 10 increased $(8 \%)$.

Table X. Frequency and percentage of types of ring shake on shoots $(n=264)$ and standards $(n=26)$.

\begin{tabular}{lcccc} 
& & & & \\
Type & \multicolumn{2}{c}{ Shoots } & \multicolumn{2}{c}{ Standards } \\
\cline { 3 - 4 } & $\mathrm{n}$ & $\%$ & $\mathrm{n}$ & $\%$ \\
& & & & \\
& & & & \\
1 & 91 & 32.7 & 19 & 14.3 \\
2 & 99 & 35.6 & 52 & 39.3 \\
3 & 40 & 14.4 & 24 & 18.1 \\
4 & 29 & 10.4 & 17 & 12.8 \\
5 & 9 & 3.2 & 6 & 4.4 \\
6 & 3 & 1.1 & 4 & 3 \\
7 & 3 & 1.1 & 0 & 0 \\
8 & 2 & 0.7 & 0 & 0 \\
9 & 1 & 0.4 & 1 & 0.7 \\
10 & 1 & 0.4 & 9 & 7.4 \\
Total & 278 & 100 & 132 & 100 \\
& & & &
\end{tabular}


Along the radius, from the pith to the bark, the cases of ring shake were distributed with unimodal frequency which positioned itself in the middle third, in agreement with what had already been found by Chanson et al (1989), Boetto (1991) and Macchioni (1992a). Both in the standards (older) and in the shoots (younger), only the portion closest to the pith $(<11-13 \%$ of the radius) and the distal portion (beyond $86-90 \%$ of the radius) were completely exempt from the phenomenon. Aggregating the data in classes of percentage of radius of an amplitude of $5 \%$, in the shoots the mode positions itself at the level of the $52.5 \%$ class $(50-55 \%$ range; fig 6 ); in the standards, instead, it shifts closer to the bark, in the $62.5 \%$ class (60-65\% range; fig 7).

This distribution, which agrees with the findings of Chanson et al (1989) and Macchioni (1992a) is to be linked to the hypothetical distribution that the growth stresses assume within the stems after felling and the strains that these stresses cause in the three anatomical directions, starting from Kubler's model (1987).

The position of ring shake with respect to the historical moment (solar year) appears to be somewhat remarkable. In shoots, as much as $50.7 \%$ of the total cases of ring
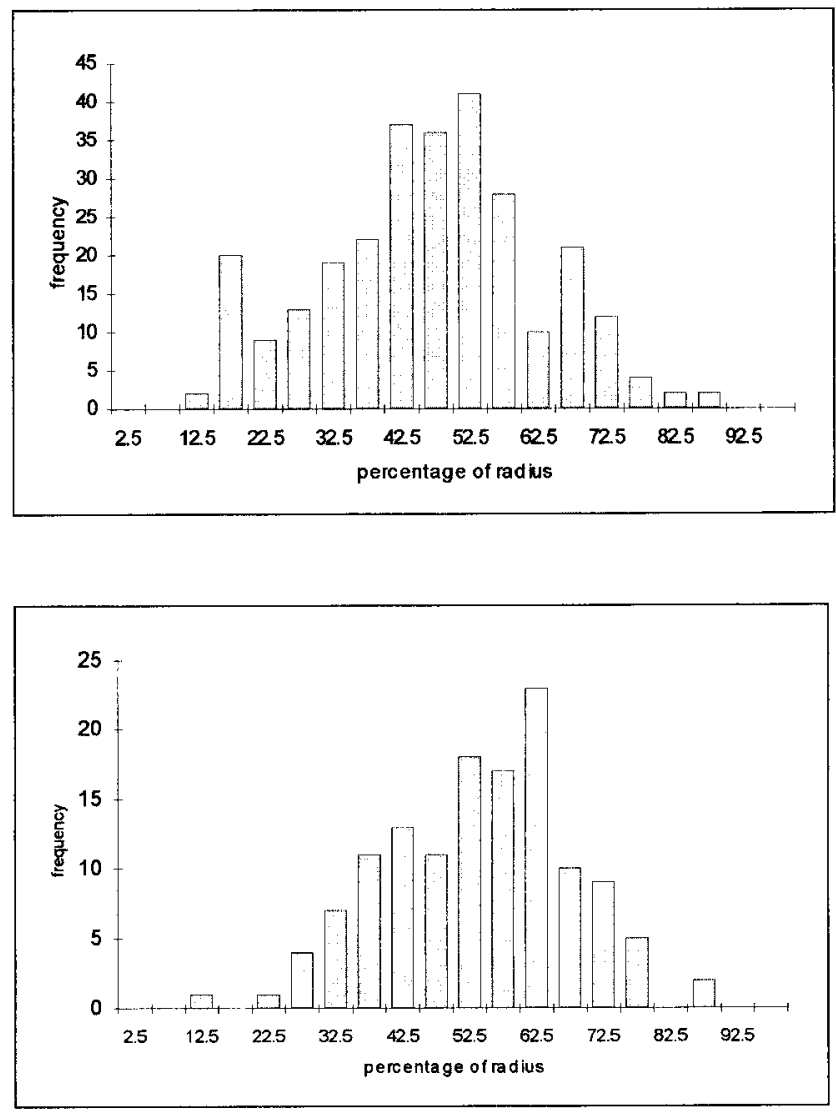

Fig 6. Absolute frequency of distribution of ring shake according to percentage classes of subdivision of radius - shoots $(n=264)$.

Fig 7. Absolute frequency of distribution of ring shake according to percentage classes of subdivision of radius - standards $(n=26)$. 
shake is found to be within the range of three consecutive years $(1971,1972,1973)$ (fig 8); in standards, we evidence an increase in the frequency of ring shake in a number of years $(1960,1963,1964,1966$, $1967,1971,1972,1973$ ) (fig 9). It is interesting to note how the period 1971-1973 emerges both in the younger stems and in the older ones. It might therefore be hypothesized that in a stem portion that is physiologically more subject to ring shake (the middle third of the radius), the external environmental conditions affecting cambial activity may have determined the onset of "weak points" predisposing to the formation of ring shake in the form of sharp incremental variations.
In concomitance with the period 1971-1973, the curve of the current increment of the radius of the shoots (fig 4) presents a minimum which, if we consider shoots affected by ring shake, is positioned approximately half way along the radius ( $48 \%$ of the radius, starting from the pith). In this connection, the observation emerging from multivariate analysis proved of interest. This analysis was carried out on all the annual increments of the shoots, which were subdivided according to classes of ring shake. Considering as a factor the values of the increments, at a general level we did not find significant differences between the three classes of shoots, but, observing the significance at the level of the individual
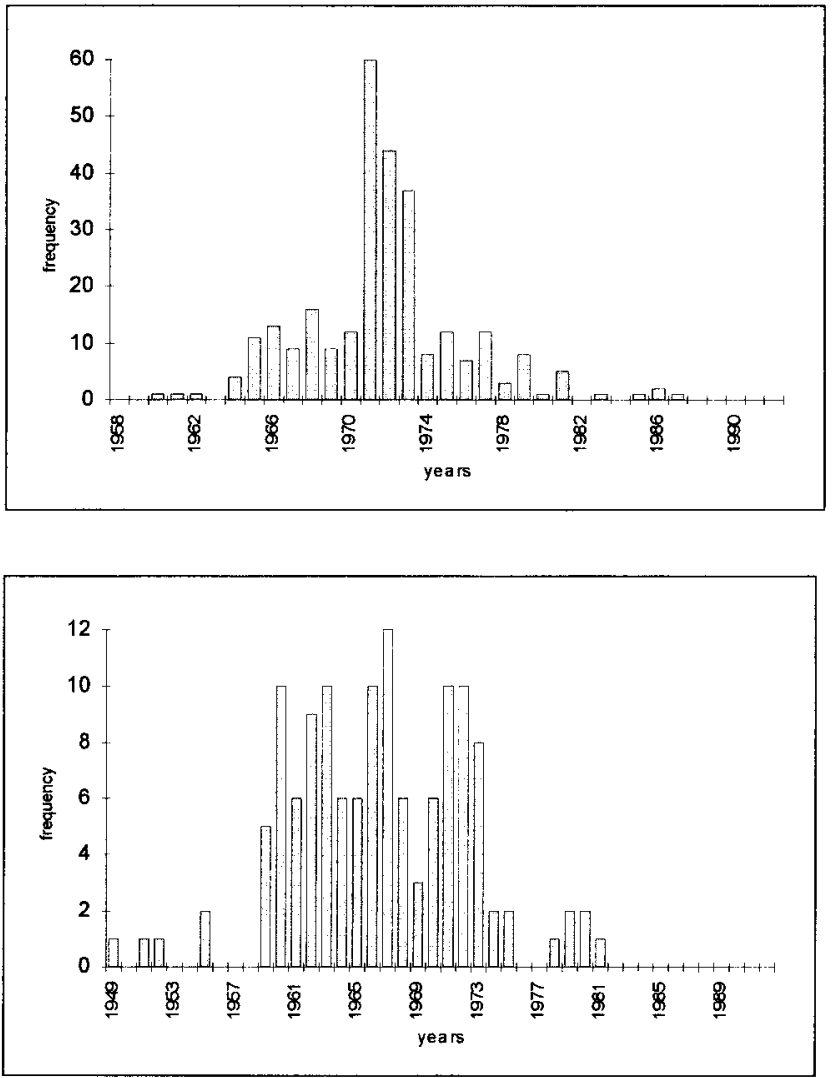

Fig 8. Distribution of ring shake over the years shoots $(n=264)$.

Fig 9. Distribution of ring shake over the years - standards $(n=26)$. 
years, there exists a difference for the period 1971-1973, in which half of the cases of ring shake occurred.

From the technological point of view, the sharp incremental variations cause adjacency of annual rings whose wood has pronounced differences in density, and hence in physicomechanical behaviour. In chestnut wood, of greater importance, however, seems to be a steep drop in increments leading to the formation of very low-density wood (in some years only the porous ring forms). This inevitably constitutes a weak point along the tangential-radial plane; the porous ring has a density of approximately one third that of the late part of the ring (on the basis of Chanson's findings, 1988). From the data examined, it therefore seems that the presence of a clear decrease in the annual increments in the portion of radius in which the incidence of internal stresses is higher constitutes an important point of onset for the development of ring shake.

\section{Characteristics and classification of stems affected by ring shake}

As already mentioned, $37.9 \%$ of the shoots and $96.1 \%$ of the standards showed ring shake. Among the shoots, 32\% (12.1\% of the total) belonged to Class 1 (little evidence of ring shake), whereas the remaining $68 \%$ $(25.7 \%$ of the total) were of Class 2 (severely affected by ring shake). Among the standards, $84 \%$ were in Class 2 and only $16 \%$ in Class 1 . It would therefore appear to be evident that ring shake is not evenly distributed throughout the population, but is concentrated over a portion of the trees, which, above all as regards standards, seems to be physiologically more predisposed to the defect, perhaps on account of the marked incremental variations occurring during growth.

On the basis of the shoot parameters (table XI), multivariate analysis of variance brings out a high level of significance between the classes of ring shake and the diameter, the height and the mean increment, whereas it is simply significant as regards sweep. The other parameters evaluated did not reveal any significant correlation, even though table $\mathrm{XI}$, which presents the mean values, would seem to indicate at least the existence of a trend for certain of these. In particular, it should be emphasized that the size of the crown represents the only parameter, among those regarding size,

Table XI. Mean values of the main parameters of shoots $(n=264)$ and standards $(n=26)$ according to class of ring shake.

\begin{tabular}{|c|c|c|c|c|c|}
\hline & 0 & 1 & 2 & Mean & Standards \\
\hline Mean diameter $(\mathrm{cm})$ & 16.7 & 18.5 & 18.9 & 17.5 & 24 \\
\hline Mean height $(m)$ & 17.2 & 18.8 & 18.5 & 17.7 & 17.8 \\
\hline Mean incr $(\mathrm{mm})$ & 2.8 & 3 & 3.2 & 2.9 & 2.3 \\
\hline CV of mean incr $(\%)$ & 44.9 & 42.4 & 44.7 & 44.6 & 58.4 \\
\hline Sweep (sagitta/height) & 0.23 & 0.19 & 0.16 & 0.2 & 0.16 \\
\hline Verticality (m) & 0.51 & 0.45 & 0.49 & 0.5 & 0.36 \\
\hline Ovality of stem & 1.06 & 1.05 & 1.06 & 1.06 & 1.06 \\
\hline Crown development along the stem (\%) & 34.4 & 39.2 & 36.1 & 35.4 & 40.9 \\
\hline Mean diameter of crown (m) & 4.5 & 4.8 & 4.7 & 4.6 & 5.9 \\
\hline
\end{tabular}

$\mathrm{CV}$ : coefficients of variation; incr: increments. 
that does not emerge as affording any possibility of correlation with the presence of ring shake.

The correlation between presence of ring shake and stem diameter has already been noted by Cielo (1992) and Macchioni (1995), and this also seems to have some connection with growth stresses, which are more marked where the diameters are larger. Likewise, there emerges a direct link between the diameter and the parameters regarding height and mean increment of the stem.

Standards (table XI) prove to have certain parameters which, on average, are differentiated from those of coppice shoots: greater diameter, verticality, percentage of crown and diameter of crown, smaller mean increment; however, these are dimensional characteristics of the stems for which it is normal that they should be clearly different from those of shoots. In fact, with Student's $t$-test, the two populations represented by the shoots and by the standards prove to be different in a highly significant way only as regards diameter and mean increment, and significant as regards sweep. For our purposes, it is more important to underline the fact that the difference between the coefficients of variation of the annual increments (newly employing Student's $t$-test on shoots and standards populations), as opposed to their standard deviation, is highly significant. We believe therefore that this index of variability of annual increments may prove more useful than the standard deviation of the increments.

In light of what has been examined in table $\mathrm{XI}$, as regards the differences in the incremental parameters of the classes of ring shake established, it seems that the existence of a relationship between the presence of ring shake and the irregularities in growth is to be ruled out. In fact, the parameters in the table represent mean values of the entire growth of the tree, and manage only to detect the presence of frequent marked variations such as those that the standards show. For this reason, the coefficient of variation of the increments does not enable identification of the differences in the growths between the types of shoots affected by ring shake; however, for these it has been possible to verify the existence of an albeit small difference between the standard deviation of the growth rates of healthy stems and that of the stems affected by ring shake in the period of years most involved in the phenomenon (1968-1977).

\section{Characteristics and classification of stools affected by ring shake}

As already mentioned, on the population under examination, $51 \%$ (43) of the stools presented shoots affected by ring shake. Of these stools, 11 (13\% of the total) belonged to Class 1, $16(19 \%)$ to Class 2 and $16(19 \%)$ to Class 3 . The distribution of coppice shoots affected by ring shake over the stools highlights how the phenomenon is concentrated in approximately one-half of the stools and that in approximately $20 \%$ of the total, practically all the shoots are affected by ring shake. It must be noted that 18 stools, out of the analysed 85 , are carrying a standard (the remaining height standards are isolated), for the $55 \%$ of which (ten stools) the standard is the only ring shaked stem.

Re-aggregating the mean data on the parameters of the stools (table XII), the distance between the stools is maintained largely constant around $4 \mathrm{~m}$. The mean height of the shoots presents a continuously increasing pattern as does the stool diameter. As far as the number of shoots in the stool, instead, is concerned, and their mean diameter, these increase from Class 0 to Class 2 and show a more or less pronounced regression in Class 3 . From what has been presented earlier, it may be noted that, on the basis of the diameter and mean height of the shoots, the shoots that have 
Table XII. Characteristics of stools $(n=85)$ on the basis of presence of ring shake.

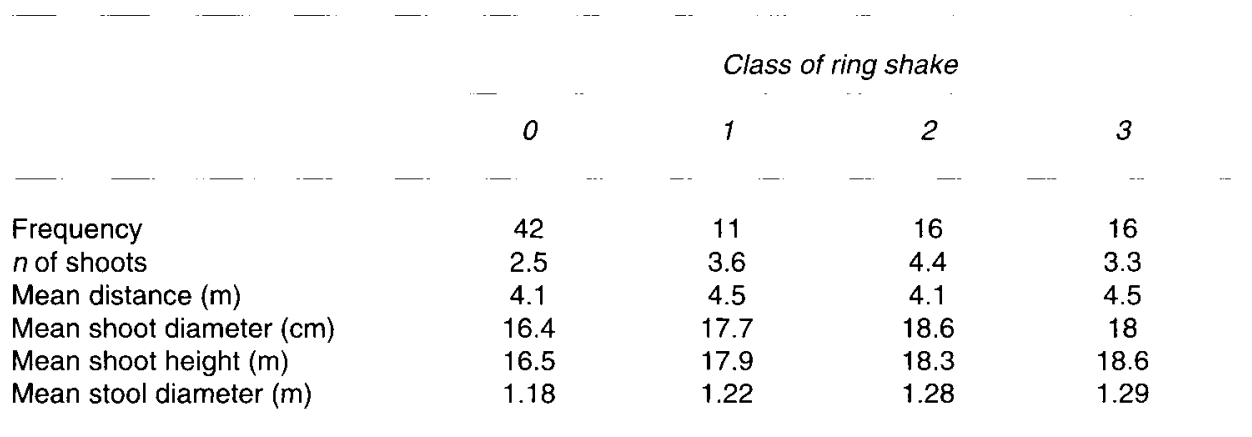

stools of smaller size reveal a lesser incidence of ring shake, whereas the most characteristic data for describing the stools, namely, the stool diameter and the number of shoots, seem to indicate that the biggest stools, and hence presumably the oldest, have a greater percentage of shoots with ring shake.

The four types of stools prove statistically separable to a significant degree on the basis of multivariate analysis of variance, but the parameters that best differentiate them are the mean height of the shoots and, above all, the number of shoots present on the stool.

The distribution over the territory of stools without shoots affected by ring shake (Class 0) (fig 10) shows a certain concentration of them in the northwest sector of the plot, where the land is slightly in relief; this comprises the entire area with 26-year-old shoots and the eastern border with 35-yearold shoots.

From the subdivision of the classes of ring shake of the stools performed on the basis of the degree of dominance of the latter (table XIII), it may be noted how the dominant and codominant stools are distributed both in the classes presenting little or no evidence of ring shake, and in the classes with a high presence of ring shake. It is interesting to see how as many as 2 dominated stools (with shoots of smaller dimensions) were among the stools most affected by ring shake (Class 3). On the basis of what has so far been presented, it would therefore seem that the social

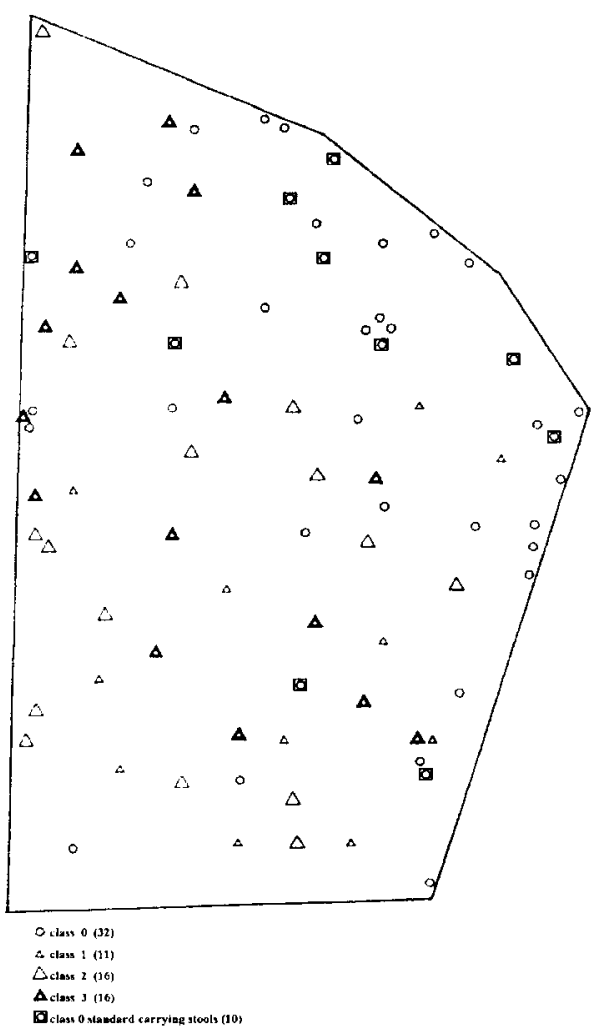

Fig 10. Location on the study area of stools subdivided into ring shake classes. 
Table XIII. Distribution (frequency) of stools with ring shake $(n=43)$ according to their social position.

\begin{tabular}{|c|c|c|c|c|}
\hline \multirow{2}{*}{\multicolumn{2}{|c|}{$\begin{array}{l}\text { Class of } \\
\text { ring shake }\end{array}$}} & \multicolumn{3}{|c|}{ Social position } \\
\hline & & $1(\%)$ & $2(\%)$ & $3(\%)$ \\
\hline ..- & - & - & - & -- \\
\hline 0 & & $11(44)$ & $19(41.3)$ & $12(85.7)$ \\
\hline 1 & & $1(4)$ & $10(21.7)$ & 0 \\
\hline 2 & & $6(24)$ & $10(21.7)$ & 0 \\
\hline 3 & & $7(28)$ & $7(15.3)$ & $2(14.3)$ \\
\hline Total & & $25(100)$ & $46(100)$ & $14(100)$ \\
\hline - & . & $\ldots-$ & - & ... \\
\hline
\end{tabular}

position of the stool is not a determining factor as regards incidence of ring shake.

From the observations conducted on the distribution of ring shake over the stools, it may be deduced therefore that the presence of stools with shoots affected by ring shake and of others without shoots presenting ring shake could be linked to endogenous factors connected with the characteristics of the cambial activity. On the other hand, the position with regard to micromorphology of the stand would also appear to have its own importance, together with the age of the stool. The result of the processes of competition between the various stools (ie, the hierarchical distribution) seems instead to have a lesser influence on the distribution of ring shake within the population. The picture that emerges prompts silvicultural intervention to reduce the risk of ring shake before the effects of interstool competition make themselves felt. It is therefore necessary to work at the level of the individual shoots, focusing attention on the growth of each stem within the stool.

\section{CONCLUSION}

The analysis of the radial increments on a dendro-ecological basis, associated to the analysis of the traditional dendrometric parameters, has highlighted how the present uniform and monoplanar structure of the population is in fact the result of silvicultural intervention (coppicing and leaving standards) carried out at various times and on different parts of the forest. The impossibility of distinguishing standards (normally coppice shoots that have expressly been left) a priori illustrates a rapid dynamics of evolution of the chestnut coppice. The number of shoots and their qualitative characteristics seem to depend upon the internal competition and the size of the stool, while their final dimensions (diameter, height and area of incidence of the crown) seem to be a consequence of the interstool competition. For a deeper study of the interaction between stools, the effects of which in this work have been studied exclusively at the epigean level, there has nevertheless emerged the need for a deeper investigation also at the level of the roots, in order to obtain a better understanding of the mechanisms whereby, in conditions of competition, the prevailing stool tends to present a more than average growth, as if it drew advantage from the resources of the succumbing stool.

The phenomenon of ring shake seems to occur in the population with a nonrandom distribution, linked to various characteristics, such as the size, age, distribution of growth stresses or growth rhythms (standards, shoots), the microstand and microenvironmental characteristics (overall fertility of the stand) and the stool to which the shoots belong (genetic characteristics). An important aspect emerging from the analysis of the results is the preferential concentration of ring shake on rings corresponding to certain years, which might in any case indicate, in addition to the factors already mentioned, a certain importance of factors linked to the climatic pattern, and hence independent of interactions within the biotic community. These factors could therefore be involved 
in the future identification of a "ring shake risk" index that may be evaluated for a population.

From the picture described here, it emerges how, in the population under study, there seem to be multiple factors affecting the incidence of ring shake in chestnut coppice stems. On some of these factors, such as, for example, the stand conditions or the genetic characteristics of the single individuals (stools), it proves practically impossible to act using normal silvicultural techniques in the context of an already existing forest. For other factors, such as growth rhythms and stem size, one might think of intervening by identifying and applying a technical cycle, which is not to be exceeded, in order to reach the desired size. During this cycle, the aim would be to anticipate natural selection by means of suitable thinning in order to keep the increments maximal and, if possible, constant.

There remains to evaluate the expediency of producing workable timber from coppice populations instead of from high forests. The possible advantages of the coppice may, in our view, be summarized as follows:

- enormous availability at present of forests of this kind, whereas timber forests would have to be constituted ex novo;

- extremely high and practically inexhaustible capacity of chestnut for generating shoots, which would inevitably lead to the constitution of a coppice at the end of each high-forest cycle, unless exceptionally burdensome interventions (eg, mechanical extirpation of the stools) were carried out;

- a rapid dynamics which enables immediate response of the population to possible silvicultural intervention;

- possibility of obtaining high-quality timber stock with relatively short cycles (20-30 years).

In the light of what has been observed within the Torre Canavese population, it would seem possible to reduce the risk of ring shake by adopting appropriate silvicultural practices and hence obtain material of good quality even from populations that at present may be considered to offer only modest prospects. In the view of the present authors, this could take place as follows: choice of the population on which to intervene on the basis of fertility parameters (such as to enable the product to be obtained within a short time), and application of cultural intervention aimed at reducing the effects of competition on the anual increments.

It should, however, be pointed out that there exists the possibility, which is at present only theoretical, of a further reduction of the risk of ring shake through intervention on other factors that seem to have a bearing on the onset of ring shake, which have not been considered in the present study.

\section{PROSPECTS}

The experimentation on the Torre Canavese population will proceed through densimetric analysis and analysis of the radial mechanical strength of the timber obtained from the shoots after coppicing. From the silvicultural standpoint, observations have been made on new coppice at two-years' distance from cutting, and, in future, clearing and thinning will be carried out in order to be able to evaluate, at the end of the next cycle, the effects of the chosen intervention.

\section{REFERENCES}

Amorini E, Fabbio G (1991) Ricerche sull'invecchiamento dei cedui : riflessi sul trattamento di conversione. L'italia Forestale e Montana 3, 193-204

Anonymus (1992) SPSS Base System Reference Guide, Release 5.0. SPSS Inc, Chicago, IL, USA, p 792

Aymard M, Fredon JJ (1986) Étude des relations entre une racine et les rejets de la souche chez Catanea sativa mill. Ann Sci For 3, 351-364 
Bagnaresi U (1977) Orientamenti selvicolturali per il miglioramento dei castagneti nell'Emilia Romagna. Monti e Boschi 1, 41-44

Bagnaresi U, Giannini R (1979) I castagneti da legno in Italia. In: Produttività e valorizzazione dei castagneti da frutto $e$ dei cedui di castagno. Accademia Nazionale di Agricoltura, Bologna, Italy, 145-178

Bagnaresi U, Bassi D, Colò V, Regazzi D, Sansavini S (1984) Ricostituzione di un castagneto da frutto: valutazioni tecnico-economiche. Frutticoltura 3-4, 3341

Bernetti G (1985) Ipotesi sullo sviluppo dei boschi cedui e relative considerazioni selvicolturali ed assestamentali. Monti e Boschi 5, 61-661

Boetto G (1991) La cipollatura del castagno : osservazioni in due boschi cedui del Piemonte. Tesi di laurea in Scienze Forestali. Università di Torino, Italy, $104 \mathrm{p}$

Bourgeois C (1992) Le chataignier, un arbre, un bois Institut pour le développement forestier, Paris, France, $355 p$

Camussi A, Möller F, Ottaviano E, Sari Gorla M (1986) Metodi statistici per la sperimentazione biologica. Zanichelli, Bologna, $488 \mathrm{p}$

Cava S, Ciancio O (1975) Osservazioni sperimentali su cedui originatisi per conversioni di castagneti da frutto. Ann Ist Sper Selv Arezzo 6, 205-228

Chanson B (1988) Étude de quelques propriétés physiques et anatomiques du bois de rejets de taillis de châtaignier (Castanea sativa Mill). Application à l'étude de la roulure. Thèse, université de Montpellier-II, France

Chanson B, Leban JM, Thibaut B (1989) La roulure du châtaignier (Castanea sativa Mill). For Méd XI, 15 34
Cielo P (1992) Ricerche sperimentali sulla cipollatura in un ceduo di castagno del Comune di Garessio (CN). Quaderni dell'/stituto di Assestamento e Tecnologia Forestale, Università di Firenze, Italy, 5, 27-44

Conedera M (1989) Danni boschivi di nuovo tipo ed inquinamento atmosferico. Sanasilva - Informazione, Bellinzona, $61 \mathrm{p}$

Conedera M (1993) Cancro corticale del castagno Principali caratteristiche epidemiologiche e misure pratiche di controllo. Berichte der WSL 335, Birmensdorf

Fenaroli L (1945) // castagno. REDA, Rome, Italy

Frascaria N, Chanson B, Thibaut B, Lefranc M (1992) Génotypes et résistance mécanique radiale du bois de châtaignier (Castanea sativa Mill). Analyse d'un des facteurs explicatifs de la roulure. Ann Sci For $49,49-62$

Giordano G (1981) Tecnologia del legno, I vol, Utet, Torino, Italy

Kubler H (1987) Growth stresses in trees and related wood properties. For Prod Abstr 10, 61-119

Macchioni N (1992a) Distribuzione della cipollatura nei fusti di castagno : analisi sperimentale. Quaderni dell'stituto di Assestamento e Tecnologia forestale, Università di Firenze, Italy, 5, 47-62

Macchioni N (1992b) Studi sulla cipollatura del castagno (Castanea sativa Mill) : metodologie per la valutazione della coesione trasversale del legno. Tesi per il conseguimento del titolo di Dottore di Ricerca, Università di Firenze, Italy, $102 \mathrm{p}$

Macchioni $N$ (1995) Mechanical strength and ring shake in chestnut (Castanea sativa Mill) wood. For Med $16,67-73$

Regione Piemonte (1981) / boschi et la carta forestale del Piemonte, Guida Editori, Naples 